\title{
Effects of the Circulation Pump Type and Ultraviolet Sterilization on Nutrient Solutions and Plant Growth in Plant Factories
}

\author{
Yu-Wei Liu and Chen-Kang Huang ${ }^{1}$
}

AdDitional INDEX wORds. Fe ions, hydroponics, ion concentration, lettuce, strawberry, UV

\begin{abstract}
SUMMARY. Hydroponic systems in plant factories can be categorized into recirculating or noncirculating systems. In this study, the effects of various commercially available circulation pumps, including a centrifugal magnetic drive pump, a regenerative self-priming pump, and a submersible pump, were experimentally explored. In addition, the effects of an ultraviolet sterilization system on the ion concentrations in nutrient solutions were examined. The concentrations of sodium, potassium, magnesium, calcium, nitrate, sulfate, and ferric $\left(\mathrm{Fe}^{3+}\right)$ ions in the nutrient solution were measured. For all three types of pumps, the results indicated that there was no significant effect on the concentrations of ions in the nutrient solution. However, the concentration of $\mathrm{Fe}^{3+}$ ions decreased significantly after the nutrient solution was treated by a ultraviolet sterilization system for 48 hours. In addition, the effects of the three types of pumps on the growth of butterhead lettuce (Lactuca sativa) were examined. The temperature records during the pump circulation tests showed that the nutrient solution temperature of the regenerative self-priming pump increased by $15.5{ }^{\circ} \mathrm{C}$ (from 20.5 to $36^{\circ} \mathrm{C}$ ), which caused yellow seedling, scorching on the leaves, and browning of the roots. The ion concentration in the nutrient solutions and total fresh weight of butterhead lettuce did not show any noticeable difference between the centrifugal magnetic drive pump and the submersible pump. In this paper, we clarify the cause of the decreasing iron concentration and provide a guideline for selecting the pump for circulating hydroponic systems in plant factories.
\end{abstract}

$\mathrm{C}$ rops grown outdoors are declining in quantity and quality because of worsening problems related to climate change and environmental deterioration (Fischer et al., 2002; Nelson et al., 2009; Rosenzweig and Liverman, 1992). Food security has become an increasingly important issue in recent years, and plant factories are considered possible solutions to food crop cultivation problems. In addition, the cultivation of fresh vegetables in dry climate areas or nonseasonal vegetables has become feasible in plant factories (Castilla and Hernandez, 2006; Wilson et al., 1992).

Received for publication 17 Dec. 2018. Accepted for publication 4 Feb. 2019

Published online 28 March 2019.

Department of Bio-Industrial Mechatronics Engineering, National Taiwan University, Taipei 10617 , Taiwan

${ }^{1}$ Corresponding author. E-mail: ckhuang94530@ntu. edu.tw.

This is an open access article distributed under the CC BY-NC-ND license (https://creativecommons.org/ licenses/by-nc-nd/4.0/).

https://doi.org/10.21273/HORTTECH04244-18
A plant factory is an enclosed plant-growing space that is typically equipped with cultivation racks, an air-conditioning system, a hydroponic system, and light-emitting diode (LED) or fluorescent lighting (Ikeda et al., 1992). This type of facility enables for the precise control of a cultivation environment in terms of irradiance, temperature, humidity, carbon dioxide concentration, and composition of the nutrient solution (Kozai et al., 2015; Yamori et al., 2014), which produces plants with minimal quality difference and in predetermined numbers. Moreover, the produce from the plant factory is cultivated without the use of pesticides and with minimal amounts of bacteria; therefore, it is edible without having to be washed. Plant factories also use a multilayered cultivation system to increase space efficiency (Despommier, 2009). In such a facility, the vertical closed cultivation system (which features the use of multilayer cultivation racks) coupled with favorable cultivation conditions that improve the turnover rate of plants helps to boost plant productivity per unit area (Goto, 2012; Kato et al., 2011).

However, the primary problem that plant factories currently face is high energy consumption. With the advent of red and blue LED lights, the energy consumption of plant factories equipped with artificial lighting has decreased, but lighting still accounts for $\approx 80 \%$ of their electricity costs (Kozai, 2007). Thus, unless the factories are designed to be more energyefficient, their products are unlikely to become competitive in price. The production cost is always a concern for a plant factory operation.

Hydroponics is a plant cultivation method primarily implemented in plant factories. The method involves using nutrient solutions instead of soil to grow plants. Compared with soilbased cultivation, hydroponics requires less water and fewer nutrients and enables efficient control of environmental factors (Jones, 2016). Hydroponic systems can be divided into recirculating and noncirculating types, depending on how they supply water and nutrients. One limitation of noncirculating hydroponic systems is that they discharge $15 \%$ to $40 \%$ of their nutrient solutions, which can cause

\begin{tabular}{llll}
\hline $\begin{array}{l}\text { Units } \\
\begin{array}{l}\text { To convert U.S. to SI, } \\
\text { multiply by }\end{array}\end{array}$ & U.S. unit & SI unit & $\begin{array}{l}\text { To convert SI to U.S., } \\
\text { multiply by }\end{array}$ \\
\hline 29.5735 & $\mathrm{fl} \mathrm{oz}$ & $\mathrm{mL}$ & 0.0338 \\
38.6807 & $\mathrm{fl} \mathrm{oz} / \mathrm{yard}^{3}$ & $\mathrm{~mL} \cdot \mathrm{m}^{-3}$ & 0.0259 \\
0.0929 & $\mathrm{ft}^{2}$ & $\mathrm{~m}^{2}$ & 10.7639 \\
3.7854 & gal & $\mathrm{L}$ & 0.2642 \\
25.4 & inch $(\mathrm{es})$ & $\mathrm{mm}$ & 0.0394 \\
41.8410 & langley $(\mathrm{s})$ & $\mathrm{kJ} \cdot \mathrm{m}^{-2}$ & 0.0239 \\
1 & $\mathrm{mmho} / \mathrm{m}$ & $\mathrm{mS} \cdot \mathrm{m}^{-1}$ & 1 \\
28.3495 & $\mathrm{oz}$ & $\mathrm{g}$ & 0.0353 \\
1 & $\mathrm{ppm}$ & $\mathrm{mg} \cdot \mathrm{kg}^{-1}$ & 1 \\
1 & $\mathrm{ppm}$ & $\mathrm{mg} \cdot \mathrm{L}^{-1}$ & 1 \\
10.7639 & $\mathrm{~W} / \mathrm{ft}^{2}$ & $\mathrm{~W} \cdot \mathrm{m}^{-2}$ & 0.0929 \\
$\left({ }^{\circ} \mathrm{F}-32\right) \div 1.8$ & ${ }^{\circ} \mathrm{F}$ & ${ }^{\circ} \mathrm{C}$ & $\left({ }^{\circ} \mathrm{C} \times 1.8\right)+32$ \\
$\left({ }^{\circ} \mathrm{F} \div 1.8\right)+255.37$ & ${ }^{\circ} \mathrm{F}$ & $\mathrm{K}$ & $(\mathrm{K}-255.37) \times 1.8$
\end{tabular}




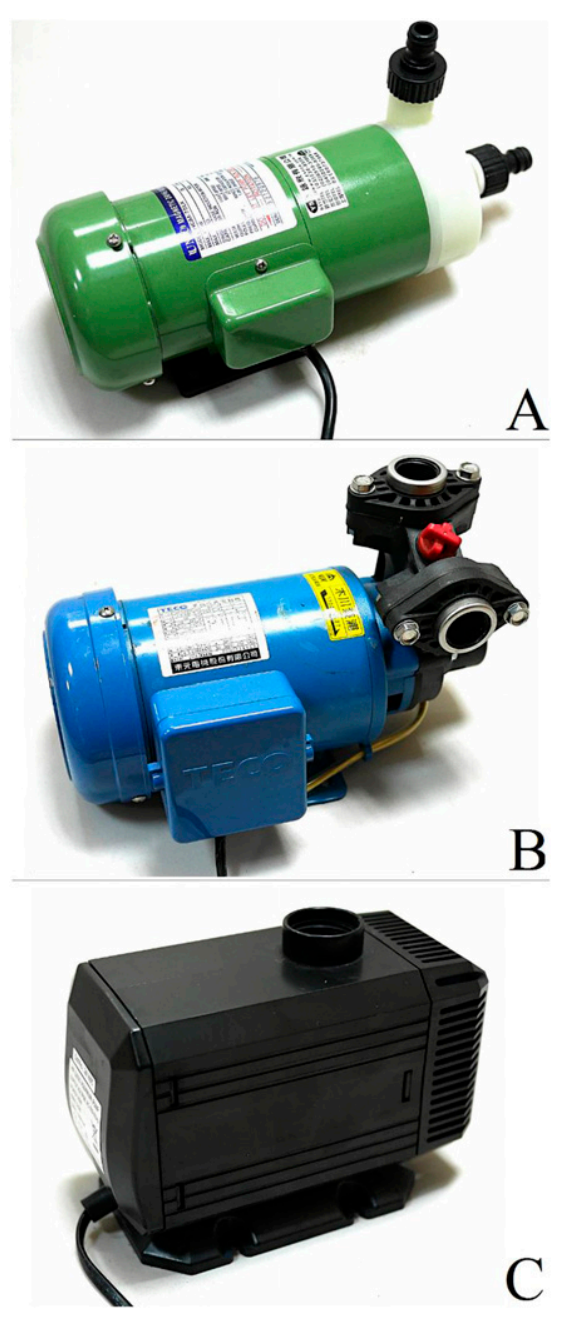

Fig. 1. Centrifugal magnetic drive water pump (A), regenerative selfpriming pump (B), and submersible water pump (C) used to study their effects on the ion concentration of nutrient solutions.

environmental problems, such as eutrophication and resource waste (Benoit, 1992; Sonneveld, 1993). Consequently, recirculating hydroponic systems are required to reduce the costs and problems associated with the discharge of water and nutrients.

Recirculating hydroponic systems return the nutrient solutions that are not absorbed by the plants to a holding tank. Measurements of the ion consumption in the nutrient solution help to determine how much water and nutrients are absorbed by the plants. A typical recirculating hydroponic system to facilitate the cultivation of leaf vegetables is the deep flow technique (DFT) hydroponic system (Ikeda, 1985; Suzuki et al., 1984). A holding tank directly below

Table 1. Composition of full-strength Enshi strawberry nutrient solution and Yamazaki lettuce nutrient solution.

\begin{tabular}{lcc}
\hline Element & Enshi concn $\left(\mathbf{m g} \cdot \mathbf{L}^{-\mathbf{1}}\right)^{\mathbf{z}}$ & Yamazaki concn $\left(\mathbf{m g} \cdot \mathbf{L}^{-\mathbf{1}}\right)$ \\
\hline Nitrogen & 245.8 & 92.2 \\
Phosphorus & 41.8 & 15.4 \\
Potassium & 312.5 & 156.2 \\
Calcium & 161.3 & 40.1 \\
Sulfur & 65.4 & 16.1 \\
Magnesium & 49.3 & 12.1 \\
Iron & 3.8 & 2.4 \\
Sodium & 1.6 & 1 \\
Boron & 0.52 & 2.8 \\
Manganese & 0.46 & 0.14 \\
Zinc & 0.05 & 0.02 \\
Copper & 0.012 & 0.01 \\
Molybdenum & 0.008 & 0.0052 \\
\hline
\end{tabular}

${ }^{2} 1 \mathrm{mg} \cdot \mathrm{L}^{-1}=1 \mathrm{ppm}$.

the planting bed can hold a large volume of nutrient solution and includes a pump to continuously or intermittently circulate the solution to ensure proper mixing.

In a closed recirculating hydroponic system, the composition of the nutrient solution tends to change over time (Cloutier et al., 1997; Son and Takakura, 1987; Zekki et al., 1996). For example, when a potato plant (Solanum tuberosum) absorbs potassium ions $\left(\mathrm{K}^{+}\right)$in large quantities from the nutrient solution, the amount of $\mathrm{K}^{+}$in the solution can decrease to a notably low level (Fong and Ulrich, 1969), which is often accompanied by the accumulation of calcium ions $\left(\mathrm{Ca}^{2+}\right)$ in the solution (Chang et al., 2011). Consequently, the ratio of $\mathrm{K}^{+}$to $\mathrm{Ca}^{2+}$ rapidly decreases in the nutrient solution, which may cause nutritional disorders in the plants. Moreover, when exudates from the plant roots accumulate in a nutrient solution, these self-produced toxins (e.g., benzoic, phthalic, and sinapic acids) can damage the plants (Jung et al., 2004; Ortega et al., 1996; Yu and Matsui, 1993), restrict the oxygen supply to the roots, and inhibit their growth (Gislerød and Kempton, 1983).

Generally, hydroponically grown crops are less likely to be contaminated with pathogens than soilgrown crops. However, whenever a plant is contaminated, pathogens can rapidly spread through the nutrient solution to neighboring plants. To prevent pathogen transmission in hydroponic systems, filters, heat, ozone, or/and ultraviolet sterilization systems are commonly used. For example, a 254-nm ultraviolet sterilization system is efficient at eliminating pathogens, which can be eliminated from a nutrient solution at an irradiance of $>2.5 \mathrm{~kJ} \cdot \mathrm{m}^{-2}$ (Runia, 1993).

In a joint research project with the Department of Horticulture and Landscape Architecture at $\mathrm{Na}$ tional Taiwan University (Taipei, Taiwan), 'Toyonoka' strawberry (Fragaria ×ananassa) was grown in a DFT hydroponic system in the university's plant factory. There, the strawberry often stopped growing and exhibited severe physiological disorders after 2 weeks. In addition to the accumulation of exudates from the roots of certain plants, other factors might severely hinder the growth of the strawberry (Hung, 2013). It was unclear whether the submersible pump to circulate the nutrient solution or the ultraviolet sterilization for the nutrient solution installed in the system accounted for this result.

In this study, the effects of various types of commercially available circulation pumps on the ion concentrations in nutrient solutions and growth of butterhead lettuce were examined. The effect of a ultraviolet sterilization system on the ions in the solution was also investigated.

\section{Materials and methods}

N U T RIE T T S O L U T I O N CIRCUlation test system. The experiment was conducted in June 2017 at the Mass and Energy Transfer Laboratory of the Department of 


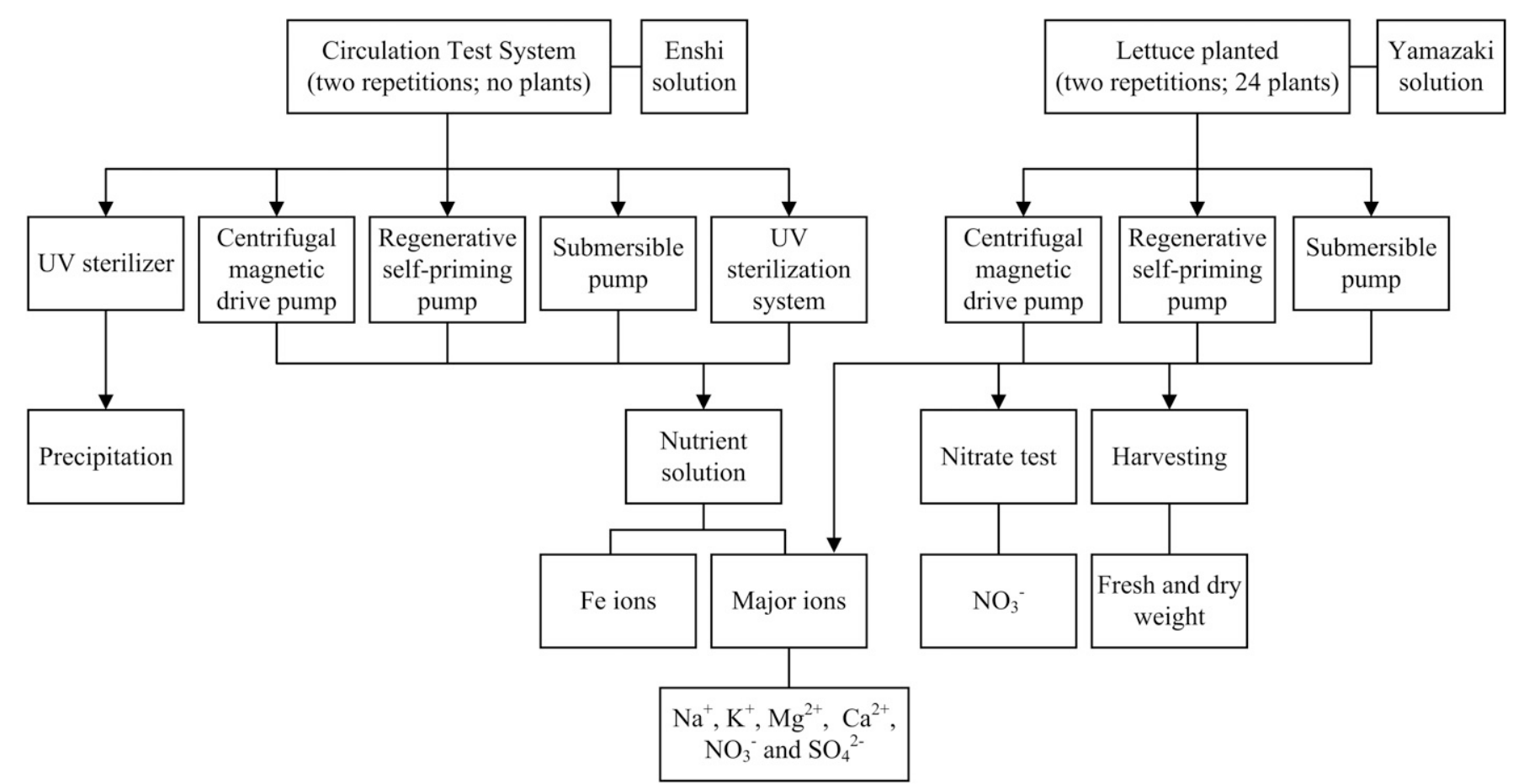

Fig. 2. Flow chart of nutrient solution and butterhead lettuce growth experiments. $\mathrm{Ca}^{2+}=$ calcium; $\mathrm{Fe}=$ iron; $\mathrm{K}^{+}=$potassium; $\mathrm{Mg}^{2+}=$ magnesium; $\mathrm{Na}^{+}=$sodium; $\mathrm{NO}_{3}{ }^{-}=$nitrate; $\mathrm{SO}_{4}{ }^{2-}=$ sulfate; $\mathrm{UV}=$ ultraviolet.

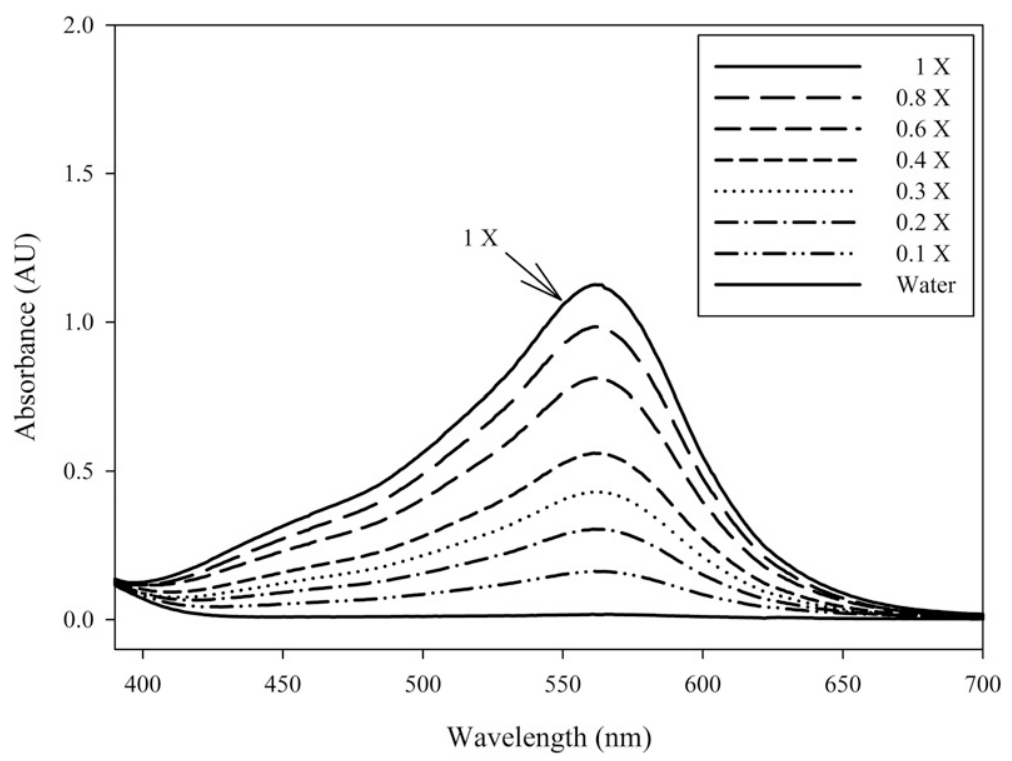

Fig. 3. Absorbance (AU) of full-strength Enshi strawberry nutrient solution at each dilution rate over the 390- to $700-\mathrm{nm}$ waveband. The photometric accuracy of spectrophotometer was \pm 0.005 absorbance.

Bio-Industrial Mechatronics Engineering, National Taiwan University, and the university's plant factory.

Three circulation pumps were tested in a series of experiments that did not involve plant production, including a $110-\mathrm{W}$ centrifugal magnetic drive pump (HCM-75LX; UNO Corp., Taichung, Taiwan) (Fig. lA), a 373-W regenerative self-priming pump (KP320NT; Kikawa Corp., Taoyuan, Taiwan) (Fig. 1B), and a $60-\mathrm{W}$ submersible pump (HP3500; Ming-Zen Corp., Taichung, Taiwan) (Fig. 1C). A 15-W ultraviolet sterilization system developed by ISTA Corporation (Tainan, Taiwan) was also used and tested. During the experiment, full-strength Enshi strawberry nutrient solution (Hori, 1966) was circulated for $5040 \mathrm{~min}$ (84 h) with an initial volume of $20 \mathrm{~L}$ and a flow rate of $800 \mathrm{~L} \cdot \mathrm{h}^{-1}$. Sampling was conducted once per $720 \mathrm{~min}$ (12 h), and eight samples were collected in total. Before sampling, the solution was refilled with deionized (DI) water to its initial level to compensate for any evaporation-induced losses. In addition, a $100 \times$ full-strength Enshi strawberry nutrient solution was stored in a beaker and irradiated by a 254-nm ultraviolet sterilizer (209b; CCIBeauty, Santa Fe Springs, CA) for $5000 \mathrm{~min}$ to observe the Fe precipitation; the ultraviolet C (UVC) intensity emitted from the ultraviolet sterilizer was $\approx 30 \mathrm{~W} \cdot \mathrm{m}^{-2}$. The salts required to prepare $1 \mathrm{~L}$ of fullstrength Enshi strawberry nutrient solution are listed in Table 1 . The series of experiments of the nutrient solution circulation test system is shown in Fig. 2.

MEASUREMENTS OF THE CONCENTRATION OF IRON (FE) IONS IN THE ENSHI STRAWBERRY NUTRIENT SOLUTION. A testing system for Fe ions (\#114759 Iron Test; Merck, Darmstadt, Germany) was used to collect samples of $6 \mathrm{~mL}$ from the nutrient solution; three drops of 


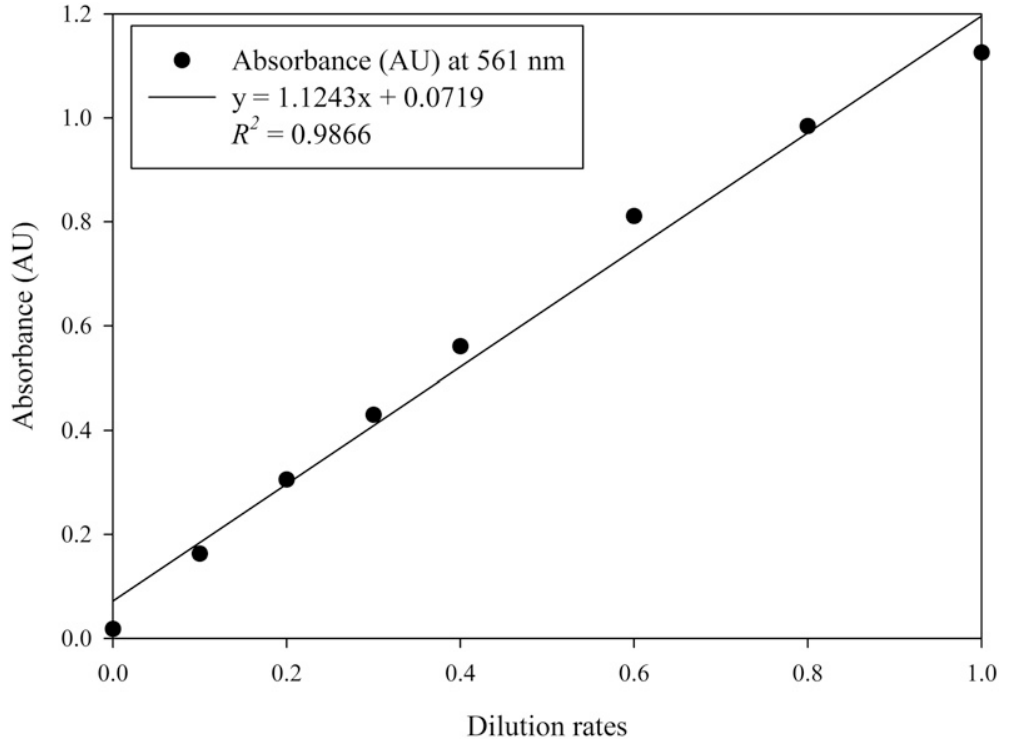

Fig. 4. Relationship between the measured absorbance (AU) of full-strength Enshi strawberry nutrient solution and dilution rates $(y=1.1243 x+0.0719$, $\left.R^{2}=0.9866\right)$.

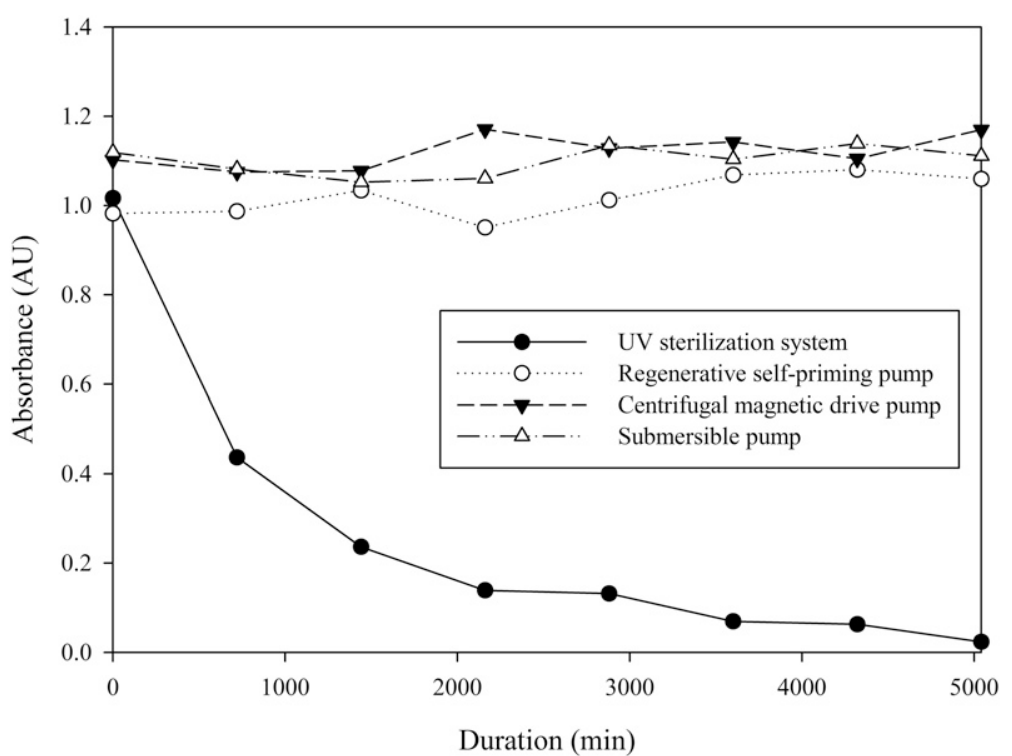

Fig. 5. Time series of iron ion absorbance (AU) at $561 \mathrm{~nm}$ of full-strength Enshi strawberry nutrient solution after circulation tests through a regenerative selfpriming pump, centrifugal magnetic drive pump, submersible pump, and ultraviolet (UV) sterilization system. Samples were obtained every $12 \mathrm{~h}$.

reagent were added to the samples. The solution and reagent were sufficiently mixed and reacted with each other for $3 \mathrm{~min}$. In this mixture, all ferric $\left(\mathrm{Fe}^{3+}\right)$ ions were reduced to ferrous $\left(\mathrm{Fe}^{2+}\right)$ ions. All $\mathrm{Fe}^{2+}$ ions subsequently reacted in a thioglycolate-buffered medium with a triazine derivative to form a red-violet complex. Then, a spectrophotometer (PRO7990; Chuan-Hua Corp., New Taipei City, Taiwan) was used to measure the absorbance of the sample across the wavelength range of 200 to $800 \mathrm{~nm}$.

ANALYSIS OF MAJOR IONS IN THE ENSHI STRAWBERRY NUTRIENT solution. The sample was diluted 20 times, and an ion analyzer (IA300 , cationic column PCI-205, anion column PCI-322; DKK-TOA Corp., Tokyo, Japan) was used to examine the change in cations [sodium $\left(\mathrm{Na}^{+}\right), \mathrm{K}^{+}$, magnesium $\left(\mathrm{Mg}^{2+}\right)$, and
$\mathrm{Ca}^{2+}$ and anions [nitrate $\left(\mathrm{NO}_{3}^{-}\right)$ and sulfate $\left.\left(\mathrm{SO}_{4}{ }^{2-}\right)\right]$ in the sample. The IA-300 ion analyzer is a smallfootprint dedicated chromatograph to measure a predefined number of ions. It can quickly and easily measure six cations or seven anions in many types of samples.

EXPERIMENTS FOR THREE DIFFERENT CIRCULATION PUMPS TO GROW BUTTERHEAD LETTUCE. A closed plant factory (spanning an area of $15.95 \mathrm{~m}^{2}$ ) in National Taiwan University was used from Apr. to July 2017, where the temperature setting was $20{ }^{\circ} \mathrm{C}$ at night and $25^{\circ} \mathrm{C}$ during the day, and the carbon dioxide $\left(\mathrm{CO}_{2}\right)$ concentration was 550 $\mathrm{mL} \cdot \mathrm{m}^{-3}$.

Seeds of butterhead lettuce were germinated and grown for $15 \mathrm{~d}$. Specifically, they were grown using pure water for the first $5 \mathrm{~d}$ in the nursery and using a full-strength Yamazaki nutrient solution for the remaining $10 \mathrm{~d}$ (Yamazaki, 1982). During the nursery period, the photoperiod was $24 \mathrm{~h}$.

After the completion of the germination period, the butterhead lettuce seedlings were shifted into a $30-\mathrm{L}$ plastic container $(1100 \mathrm{~mm}$ long, $700 \mathrm{~mm}$ wide, and $90 \mathrm{~mm}$ high), and a polystyrene foam floating board $(1070 \times 520 \times 30 \mathrm{~mm})$ was placed on top of the nutrient solution. The plant roots were inserted into the nutrient solution, and the shoots protruded above the foam board. Twelve butterhead lettuce seedlings were planted on each tray, and two trays of seedlings were placed in two shelves of a rack. The growth period was $20 \mathrm{~d}$ with a daily photoperiod of $16 \mathrm{~h}$.

During the 20-d growth period, one of three circulation pumps was tested and used to circulate the nutrient solution. The other two pumps were tested in other new growth periods. The nutrient solution tank was $90 \mathrm{~L}$ in capacity. Each of the two water trays was $30 \mathrm{~L}$ in capacity. The total amount of nutrient solution was $150 \mathrm{~L}$. The solution was full-strength Yamazaki's lettuce nutrient solution with an initial electrical conductivity of $110 \mathrm{mS} \cdot \mathrm{m}^{-1}$, and sodium hydroxide $(\mathrm{NaOH})$ or sulfuric acid $\left(\mathrm{H}_{2} \mathrm{SO}_{4}\right)$ was used to adjust the $\mathrm{pH}$ value (WM-32EP; TOA-DKK Corp., Tokyo, Japan) to 6 . The flow rate of the nutrient solution was controlled 
through valves in the supply lines to the pumps at $2800 \mathrm{~L} \cdot \mathrm{h}^{-1}$. After 35 $\mathrm{d}$ of cultivation, the butterhead lettuce plants were harvested, and their total fresh weight, total dry weight, and nitrate concentrations (through a nitrate test) were measured. Each recirculating system had two replicates, and each replicate had 24 plants. The salts required to prepare 1 L of full-strength Yamazaki nutrient solution are listed in Table 1 . The series of experiments of growing butterhead lettuce is shown in Fig. 2.

Light source. Twenty-eightwatt T5 fluorescent tubes (Wellypower, Hsinchu, Taiwan) with a color temperature of $6500 \mathrm{~K}$ were used to irradiate the plantlets with an average photosynthetically active radiation $(P A R)$ intensity of $250 \mu \mathrm{mol} \cdot \mathrm{m}^{-2} \cdot \mathrm{s}^{-1}$. The intensity was measured by a calibrated PAR meter (LI-250A; LI-COR, Lincoln, NE).

$\mathrm{NO}_{3}{ }^{-}$CONCENTRATION MEASUREMENT. $\mathrm{NO}_{3}{ }^{-}$ions were reduced to nitrite ions using a reducing agent. With an acidic buffer, these nitrite ions reacted with an aromatic amine to form a diazonium salt, which subsequently reacted with $\mathrm{N}$-(1-naphthyl)-ethylene-diamine to form a red-violet azo dye that was measured by ultraviolet reflectometry (\#116971 Nitrate Test; Merck, Darmstadt, Germany).

Statistical analysis. The Excel (Microsoft Corp., Redmond, WA) software suite was used for experimental analysis. Two recirculating systems had two replicates, and each replicate grew 24 plants. There were 24 plants in a batch of experiments. Twenty of them were selected to measure the total fresh weight, total dry weight, and tissue $\mathrm{NO}_{3}^{-}$concentration and thereafter statistics $(\mathrm{n}=$ $20)$. The significance of differences was compared using the $t$ test at the 95\% confidence level.

\section{Results \\ Nutrient solution circulation test system}

M E A S U R I N G T H E CONCENTRATION OF Fe IONS IN THE ENSHI STRAWBERRY NUTRIENT sOLUTion. Full-strength Enshi strawberry nutrient solution was diluted and reacted with the iron test reagent. The absorbance of the solution at dilution rates of 1 ( $100 \%$ solution),
$0.8,0.6,0.4,0.3,0.2,0.1$, and 0 (pure water) was measured using a spectrophotometer; the measurement results are shown in Fig. 3. The results indicate that before the dilution, the Enshi strawberry nutrient solution had an $\mathrm{Fe}$ ion concentration of $3.8 \mathrm{mg} \cdot \mathrm{L}^{-1}$ and an absorbance of 1.13 at a local peak wavelength of $561 \mathrm{~nm}$. Notably, the measured absorbance of the nutrient solution is linearly related to its dilution rate (Fig. 4).

The spectrophotometer was also used to examine the changes in absorbance of the nutrient solution every $12 \mathrm{~h}$ after the circulation tests with a regenerative self-priming pump, a centrifugal magnetic drive pump, a submersible pump, or the ultraviolet sterilization system (Fig. 5). The results indicate that the three pumps had no apparent effect on the Fe content of the nutrient solution. After the circulation with one of the three pumps, all three nutrient solutions maintained the absorbance of $\approx l$ at a wavelength of $561 \mathrm{~nm}$.

In contrast, the absorbance of the nutrient solution noticeably changed after a circulation test with the ultraviolet sterilization system driven by a submersible pump. After the nutrient solution was circulated by the system for $24 \mathrm{~h}$, its absorbance decreased from 1 to 0.2 ; after another

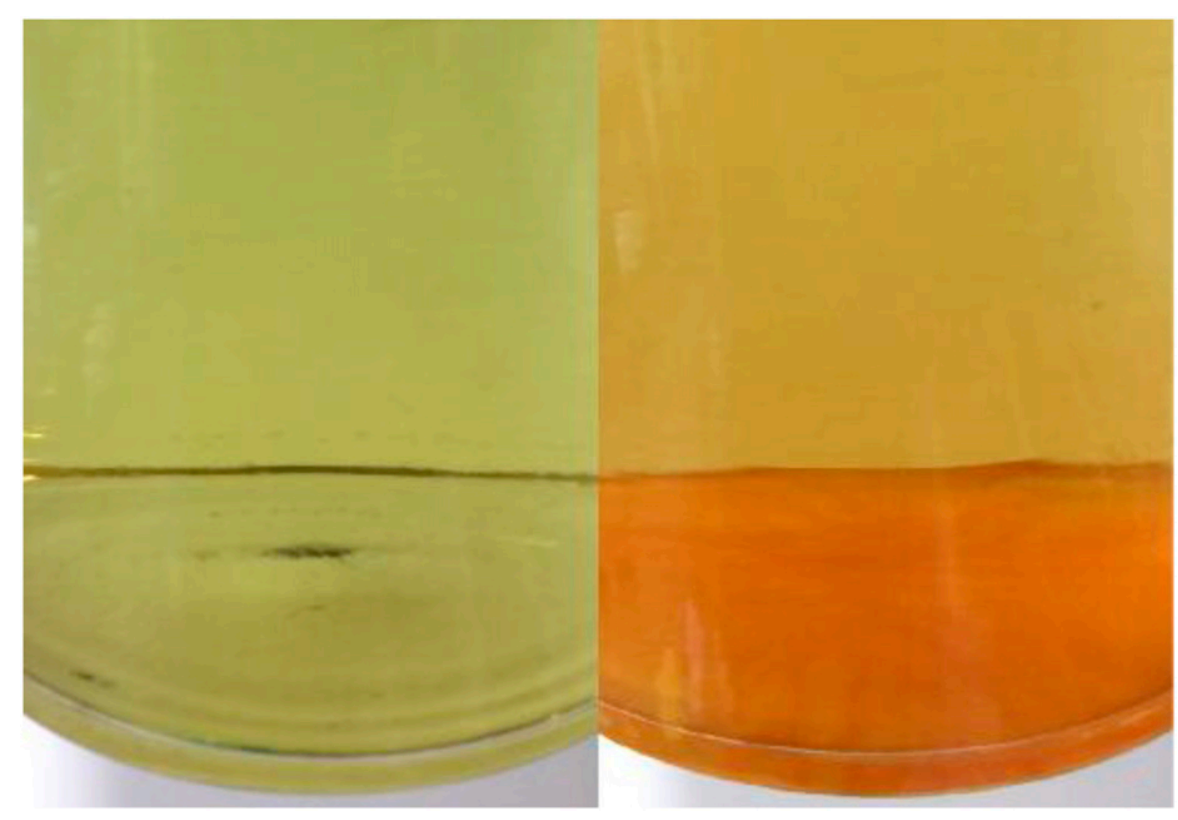

Fig. 6. Precipitation of 100X full-strength Enshi strawberry nutrient solution irradiated by an ultraviolet sterilizer [before irradiation (left), after irradiation (right) for $5000 \mathrm{~min}$ ].
$24 \mathrm{~h}$ of circulation, it further decreased to 0.1 . Furthermore, the $100 \times$ full-strength Enshi strawberry nutrient solution was stored in a beaker and placed in a ultraviolet sterilizer. After the ultraviolet irradiation, precipitation was found at the bottom of the beaker (Fig. 6). The results indicate that the ultraviolet sterilization system significantly affects the $\mathrm{Fe}$ concentration in the nutrient solution.

ANALYSIS OF MAJOR IONS IN THE ENSHI STRAWBERRY NUTRIENT solution. The ion analyzer was used to analyze the cation and anion concentrations of full-strength Enshi strawberry nutrient solution at an interval of $12 \mathrm{~h}$ after the circulation tests through the regenerative self-priming pump (Fig. 7A), centrifugal magnetic drive pump (Fig. 7B), submersible pump (Fig. 7C), and ultraviolet sterilization system (Fig. 8). The results indicate that the three pumps and sterilization system have no significant effect on the concentrations of major ions in the solution, particularly the cations $\mathrm{Na}^{+}, \mathrm{K}^{+}, \mathrm{Mg}^{2+}$, and $\mathrm{Ca}^{2+}$ and anions $\mathrm{NO}_{3}{ }^{-}$and $\mathrm{SO}_{4}{ }^{2-}$ (Table 2).

EXPERIMENTS USING THREE DIFFERENT CIRCULATION PUMPS TO GROW BUTTERHEAD LETTUCE. The plants performed poorly when the self-regenerative pump was used to 


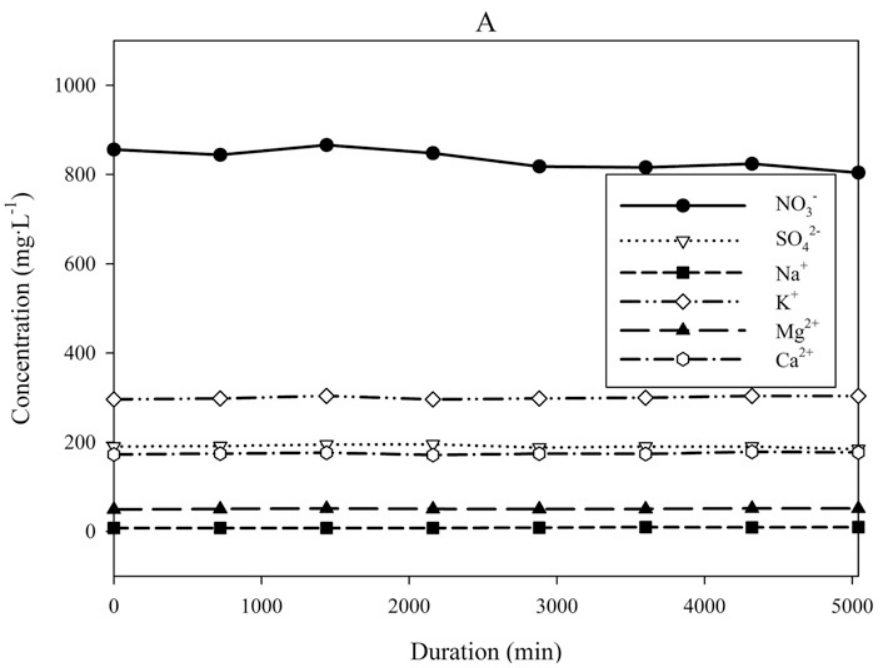

B
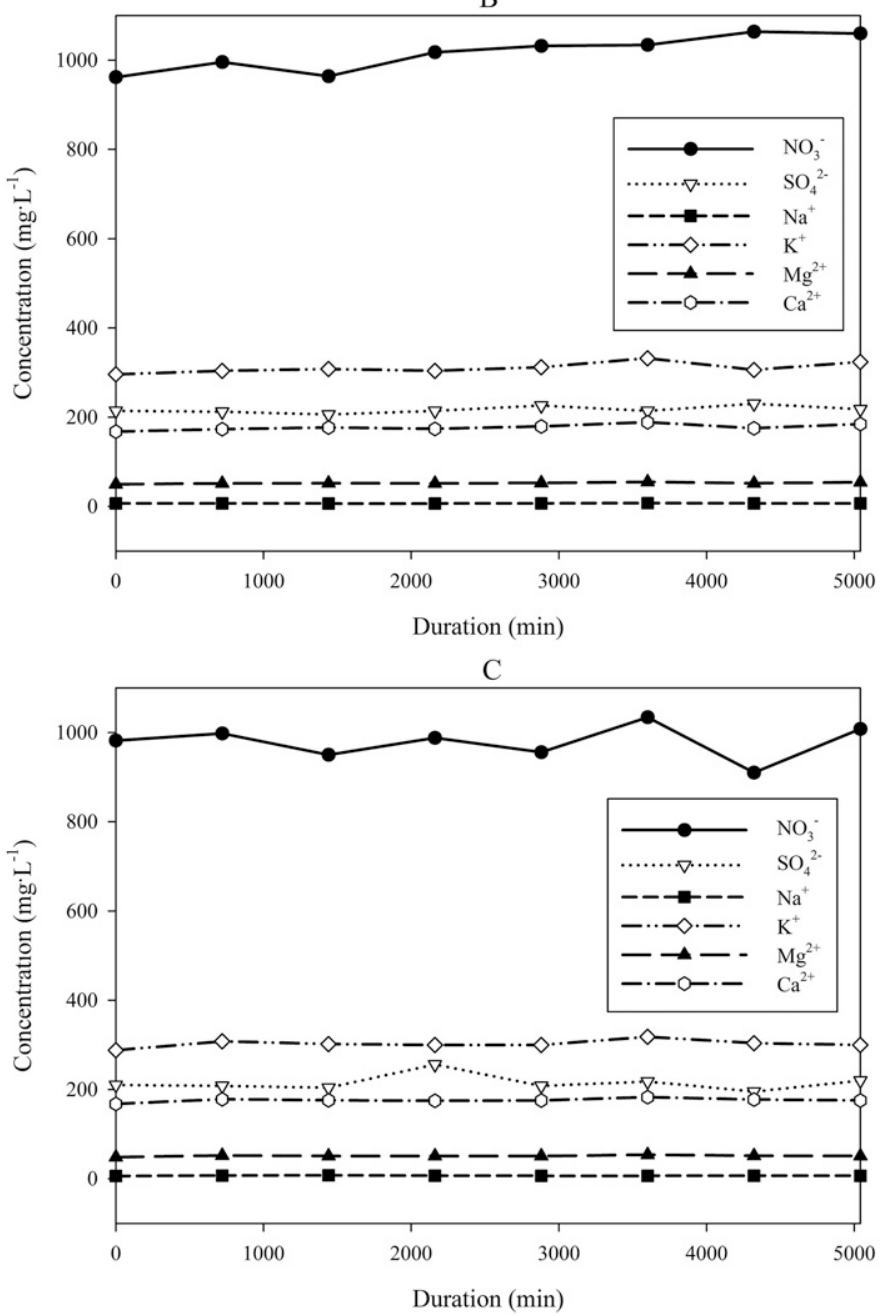

Fig. 7. Time series of selected ion concentrations of full-strength Enshi strawberry nutrient solution after a circulation tests through a regenerative self-priming pump (A), centrifugal magnetic drive water pump (B), and submersible water pump (C). Samples were obtained every $12 \mathrm{~h} . \mathrm{Ca}^{2+}=$ calcium; $\mathrm{K}^{+}=$potassium; $\mathrm{Mg}^{2+}=$ magnesium; $\mathrm{Na}^{+}=$sodium; $\mathrm{NO}_{3}{ }^{-}=$nitrate; $\mathrm{SO}_{4}{ }^{2-}=$ sulfate; $1 \mathrm{mg} \cdot \mathrm{L}^{-1}=1 \mathrm{ppm}$.

recirculate the nutrient solution, so the following results are from the experiments with the other two pumps. The ion analyzer was used to assess the changes in ion concentration of full-strength Yamazaki's lettuce nutrient solution when the butterhead lettuce seedlings were planted with the centrifugal magnetic drive pump (Fig. 9) or submersible pump (Fig. 10). The results indicate that a $20-\mathrm{d}$ circulation through both pumps induced similar changes in ion concentration of the nutrient solution. The concentrations of $\mathrm{NO}_{3}{ }^{-}$and $\mathrm{K}^{+}$slightly decreased, whereas the concentration of $\mathrm{SO}_{4}{ }^{2-}$ and $\mathrm{Ca}^{2+}$ slightly increased. In contrast, the $\mathrm{Na}^{+}$and $\mathrm{Mg}^{2+}$ concentrations showed no noticeable change.

Regarding the harvest results of the butterhead lettuce planted with the centrifugal magnetic drive and submersible pumps (Table 3), the total fresh weight of the lettuce was $100 \mathrm{~g}$, which is generally a good fresh weight in plant factories (Choi et al., 2000; Kang et al., 2013). This result suggests no significant statistical difference between the two pumps.

Moreover, the $\mathrm{NO}_{3}{ }^{-}$concentration in the foliage of butterhead lettuce planted with both pumps was $>3024 \mathrm{mg} \cdot \mathrm{L}^{-1}$, which indicates that the nutrient solution was indeed absorbed through the root (Salisbury and Ross, 1992). The results show no significant statistical difference between centrifugal magnetic drive and submersible pumps.

Figure 11 shows lettuce seedlings grown using the regenerative self-priming pump. After $4 \mathrm{~d}$ of cultivation, the seedling exhibited noticeable yellowing and scorching on the leaves and browning on the root largely because the regenerative selfpriming pump increased the temperature of the nutrient solution by $15.5{ }^{\circ} \mathrm{C}$ (compared with the increases of 2.9 and $3.7^{\circ} \mathrm{C}$ induced by the centrifugal magnetic drive and submersible pumps, respectively) to $36{ }^{\circ} \mathrm{C}$. The energy lost in friction and hydraulic losses transforms to heat, and regenerative self-priming pumps are designed to deliver their waste heat into the working fluid (Engineering ToolBox, 2006). For this study, the limited heat dissipation paths and small total water volume caused a significant temperature increase.

\section{Discussion}

N U T R I E N T S OL U T I O N CIRCULATION TEST SYSTEM. In the literature, the ultraviolet irradiation causes the Fe concentration to decline and $\mathrm{Fe}$ to precipitate in the solution 
(Kozai et al., 2015). Irradiated by ultraviolet light, the nutrient solution produces oxides (such as hydroxyl radicals), which make its chelated Fe destabilize, degrade, and release $\mathrm{Fe}^{3+}$ ion into the solution (Acher et al., 1997). $\mathrm{Fe}^{3+}$ tends to bind with other compounds [e.g., oxygen $\left(\mathrm{O}_{2}\right)$, hydroxide $\left(\mathrm{OH}^{-}\right)$, bicarbonate $\left(\mathrm{HCO}_{3}^{-}\right)$, phosphate $\left(\mathrm{PO}_{4}{ }^{3-}\right)$, and $\left.\mathrm{SO}_{4}{ }^{2-}\right]$ in a nutrient solution to precipitate as amorphous, water-containing $\mathrm{Fe}_{2} \mathrm{O}_{3}$ (Bolt and Bruggenwert, 1978; Kirk et al., 1990). The experimental results in this work are consistent with the findings in the literature.

EXPERIMENT USING THREE DIFFERENT CIRCULATION PUMPS TO GROW BUTTERHEAD LETTUCE. The insignificant changes in concentrations of these ions in the nutrient solution may result from the low density of the lettuce $\left(17\right.$ plants $\left./ \mathrm{m}^{2}\right)$ in multilayer racks in the plant factory. Therefore, the ions were absorbed by the lettuce in limited quantities.

The submersible pump costs $\approx \$ 46$, which is much cheaper than the centrifugal magnetic drive pump $(\approx \$ 116)$. Because the lettuce planted with the two pumps showed no significant difference, the less expensive submersible pump is a worthy option from the perspective of production costs. Meanwhile, a regenerative selfpriming pump was $\approx \$ 70$; however, because of the side effects of the elevated nutrient temperature, use of this pump is not recommended in the plant factory. Considering the capability and cost, the submersible pump is recommended for plant factories.

The temperature of the nutrient solution directly affects root respiration. When the temperature of the nutrient solution exceeds $29^{\circ} \mathrm{C}$, root respiration is accelerated, which

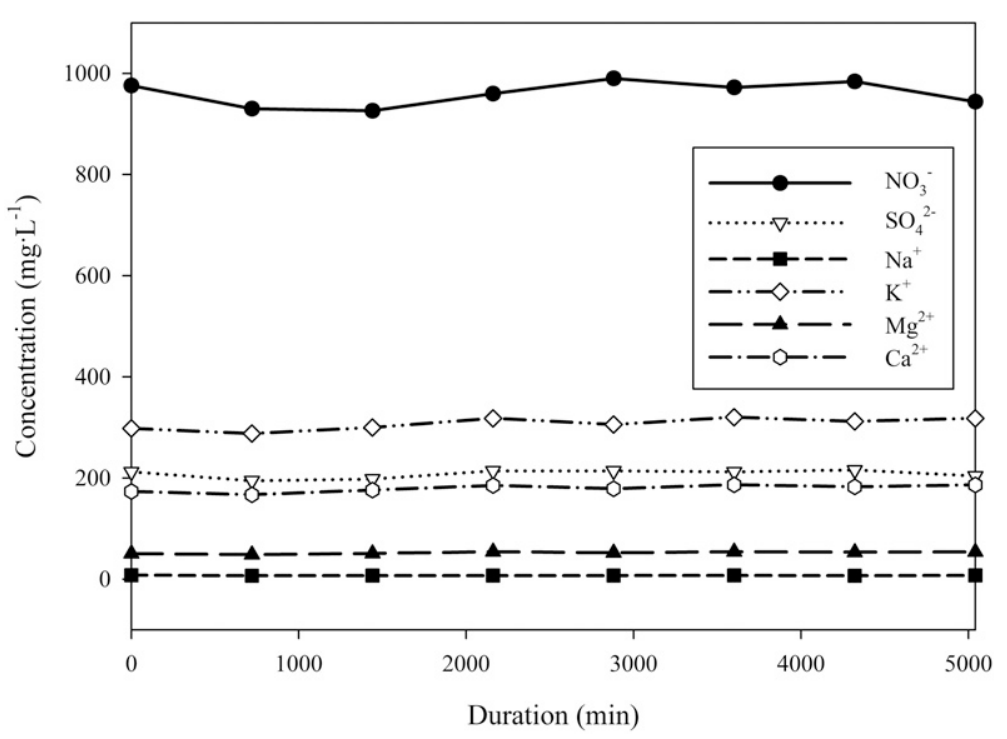

Fig. 8. Time series of ion concentrations of full-strength Enshi strawberry nutrient solution after circulation tests through an ultraviolet sterilization system. Samples were obtained every $12 \mathrm{~h} . \mathrm{Ca}^{2+}=$ calcium; $\mathrm{K}^{+}=$potassium; $\mathrm{Mg}^{2+}=$ magnesium; $\mathrm{Na}^{+}=$sodium; $\mathrm{NO}_{3}{ }^{-}=$nitrate; $\mathrm{SO}_{4}{ }^{2-}=$ sulfate; $1 \mathrm{mg} \cdot \mathrm{L}^{-1}=1 \mathrm{ppm}$. decreases the content of dissolved oxygen in the solution and causes browning and limited growth in the root; a decrease in temperature of the nutrient solution leads to a significant reduction in leaf scorching (Jensen and Malter, 1995). Meanwhile, studies have shown that increasing the temperature of the root improves the production of pepper (Capsicum annuum) plants that are grown in a greenhouse and outdoors. When the environmental temperatures during the daytime and nighttime are 23 and $19{ }^{\circ} \mathrm{C}$, there is a $30 \%$ production increment (Gosselin, 1986), and the harm of excessively low evening temperatures is attenuated to tomatoes (Jones, 1978). Therefore, for regions with high latitudes and altitudes, regenerative self-priming pumps can be used to increase the temperature of hydroponic nutrient solutions to save on heating costs.

This study investigated and discussed the effects of the centrifugal magnetic drive pump, regenerative self-priming pump, submersible pump, and ultraviolet sterilization system on the hydroponic nutrient solutions, and it demonstrated the use of the pumps for planting butterhead lettuce. The conclusions from the findings are as follows.

First, after the nutrient solutions were circulated for 5000 consecutive min by the three pumps, their concentrations of $\mathrm{Fe}$ ions showed no marked variations.

Second, the concentrations of Fe ions in the nutrient solutions decreased to $20 \%$ of their initial levels after the solutions were circulated through a ultraviolet sterilization system for $24 \mathrm{~h}$ and fell to below $10 \%$ of the original value after another $24 \mathrm{~h}$ of circulation through the system. Thus, the ultraviolet sterilization system should be operated before the Fe ions are added to the nutrient solution.

Table 2. Ion concentrations of full-strength Enshi strawberry nutrient solution after a circulation test through a regenerative self-priming pump, centrifugal magnetic drive water pump, submersible water pump, or ultraviolet sterilization system.

\begin{tabular}{|c|c|c|c|c|c|c|}
\hline \multirow[b]{2}{*}{ System $^{z}$} & \multicolumn{6}{|c|}{ Ion concn $\left[\text { mean } \pm S E\left(m g \cdot \mathrm{L}^{-1}\right)\right]^{\mathrm{y}}$} \\
\hline & $\mathrm{NO}_{3}{ }^{-}$ & $\mathrm{SO}_{4}{ }^{2-}$ & $\mathrm{Na}^{+}$ & $\mathbf{K}^{+}$ & $\mathrm{Mg}^{2+}$ & $\mathrm{Ca}^{2+}$ \\
\hline Regenerative self-priming pump & $834.50 \pm 7.77$ & $190.75 \pm 1.20$ & $8.61 \pm 0.34$ & $300.00 \pm 1.25$ & $50.85 \pm 0.27$ & $174.95 \pm 0.82$ \\
\hline Submersible pump & $978.25 \pm 13.66$ & $214.90 \pm 6.48$ & $6.83 \pm 0.18$ & $302.50 \pm 2.99$ & $51.23 \pm 0.52$ & $176.00 \pm 1.51$ \\
\hline Ultraviolet sterilization system & $960.25 \pm 8.65$ & $208.05 \pm 2.89$ & $7.27 \pm 0.13$ & $307.50 \pm 4.07$ & $52.25 \pm 0.74$ & $179.60 \pm 2.48$ \\
\hline
\end{tabular}

${ }^{\mathrm{z}}$ Each recirculating systems had two replicates, and samples were obtained every $12 \mathrm{~h}$.

${ }^{\mathrm{y}} \mathrm{Ca}^{2+}=$ calcium; $\mathrm{K}^{+}=$potassium; $\mathrm{Mg}^{2+}=$ magnesium; $\mathrm{Na}^{+}=$sodium; $\mathrm{NO}_{3}{ }^{-}=$nitrate; $\mathrm{SO}_{4}{ }^{2-}=$ sulfate; $1 \mathrm{mg} \cdot \mathrm{L}^{-1}=1 \mathrm{ppm}$ 


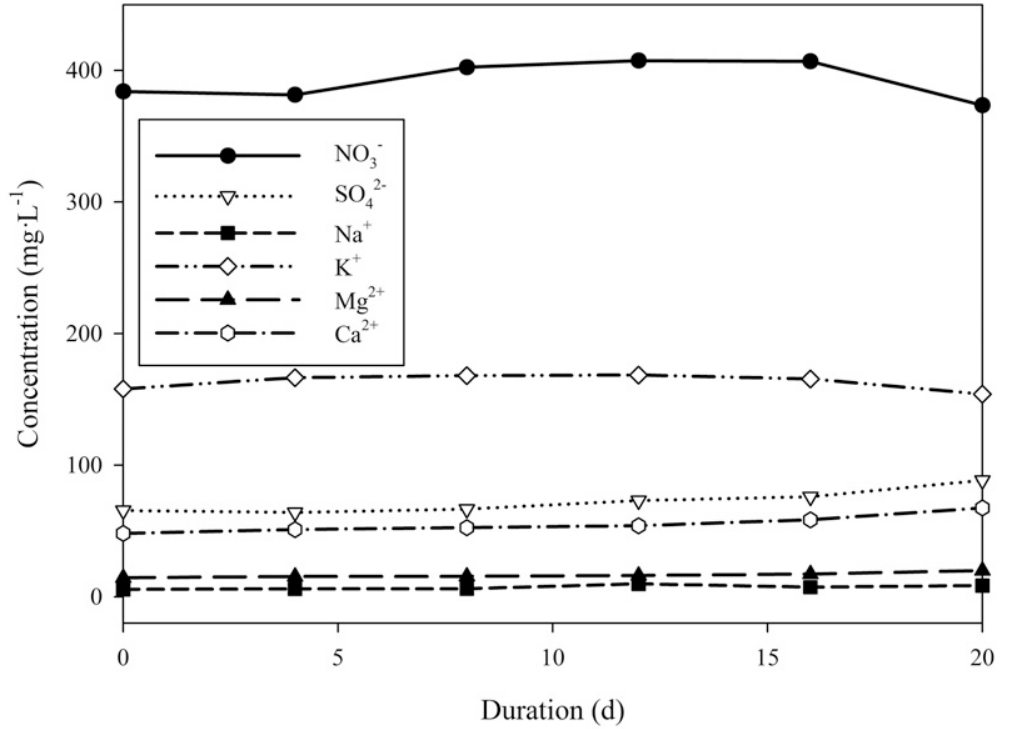

Fig. 9. Time series of ion concentrations of full-strength Yamazaki lettuce nutrient solution planted with a centrifugal magnetic drive pump. Samples were obtained every 4 d. $\mathrm{Ca}^{2+}=$ calcium; $\mathrm{K}^{+}=$potassium; $\mathrm{Mg}^{2+}=$ magnesium; $\mathrm{Na}^{+}$= sodium; $\mathrm{NO}_{3}{ }^{-}=$nitrate; $\mathrm{SO}_{4}{ }^{2-}=$ sulfate; $1 \mathrm{mg} \cdot \mathrm{L}^{-1}=1 \mathrm{ppm}$.

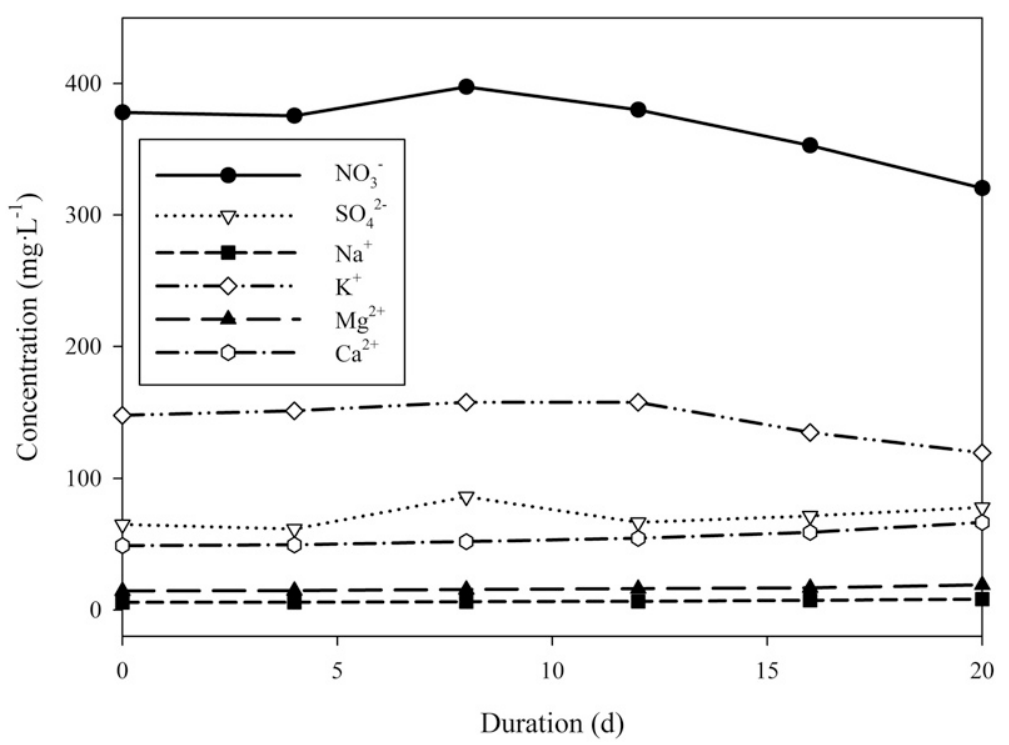

Fig. 10. Time series of ion concentrations of full-strength Yamazaki lettuce nutrient solution planted with a submersible pump. Samples were obtained every 4 d. $\mathrm{Ca}^{2+}=$ calcium $; \mathrm{K}^{+}=$potassium $; \mathrm{Mg}^{2+}=$ magnesium $; \mathrm{Na}^{+}=$sodium; $\mathrm{NO}_{3}{ }^{-}=$ nitrate; $\mathrm{SO}_{4}{ }^{2-}=$ sulfate; $1 \mathrm{mg} \cdot \mathrm{L}^{-1}=1 \mathrm{ppm}$.

Table 3. Measurements of harvested butterhead lettuce planted with centrifugal magnetic drive and submersible pumps.

\begin{tabular}{lccc}
\hline Pump system $^{\mathbf{z}}$ & $\begin{array}{c}\text { Total fresh } \\
\text { wt }(\mathbf{g})^{\mathbf{y}}\end{array}$ & $\begin{array}{c}\text { Total dry } \\
\text { wt }(\mathbf{g})\end{array}$ & $\begin{array}{c}\text { Nitrate } \\
(\mathbf{p p m})^{\mathbf{y}}\end{array}$ \\
\hline $\begin{array}{l}\text { Submersible pump } \\
\text { Centrifugal magnetic drive }\end{array}$ & 105.36 & 4.69 & $3,024.00$ \\
$\begin{array}{l}\text { pump } \\
\text { Significant }\end{array}$ & 106.63 & 5.02 & $3,101.00$ \\
\hline
\end{tabular}

${ }^{\mathrm{z}}$ Two recirculating systems had two replicates, and each replicate had 24 plants.

${ }^{\mathrm{y}} \mathrm{l} \mathrm{g}=0.0353 \mathrm{oz}, \mathrm{l} \mathrm{ppm}=1 \mathrm{mg} \cdot \mathrm{kg}^{-1}$

${ }^{x}$ The significant difference at $P \leq 0.05$ was according to the $t$ test; NS = not significant.
Third, no significant change occurred in the concentrations of major cations $\left(\mathrm{Na}^{+}, \mathrm{K}^{+}, \mathrm{Mg}^{2+}\right.$, and $\left.\mathrm{Ca}^{2+}\right)$ and major anions $\left(\mathrm{NO}_{3}{ }^{-}\right.$and $\left.\mathrm{SO}_{4}{ }^{2-}\right)$ in the nutrient solutions after circulation through the three pumps and ultraviolet sterilization system.

Fourth, both centrifugal magnetic drive and submersible pumps were used to plant butterhead lettuce; the concentration of ions in the nutrient solutions and the total fresh weight of the vegetables did not show any noticeable difference between the pumps. The submersible pumps do not affect the ion concentrations in the nutrient solution. Thus, both pumps can be used to circulate nutrient solutions for hydroponic systems, although the less expensive submersible pump is a more favorable choice considering cost.

Fifth, the regenerative self-priming pump increased the nutrient solution temperature of butterhead lettuce by $15.5^{\circ} \mathrm{C}$ (from 20.5 to $36^{\circ} \mathrm{C}$ ), which subsequently caused the roots to brown and its foliage to become yellow and scorched. Therefore, this type of pump may not be suitable for hydroponic systems in which low nutrient solution temperatures are required.

\section{Literature cited}

Acher, A., B. Heuer, E. Rubinskaya, and E. Fischer. 1997. Use of ultraviolet-disinfected nutrient solutions in greenhouses. J. Hort. Sci. 72:117-123.

Benoit, F. 1992. Practical guide for simple soilless culture techniques. European Vegetable Res. Dev. Centre, Sint-Katelijne-Waver, Belgium.

Bolt, G.H. and M.G.M. Bruggenwert. 1978. Soil chemistry. A. Basic elements. Elsevier, Amsterdam, The Netherlands.

Castilla, N. and J. Hernandez. 2006. Greenhouse technological packages for high-quality crop production. XXVII Intl. Hort. Congr. 761:285-297.

Chang, D.C., I.C. Cho, J.-T. Suh, S.J. Kim, and Y.B. Lee. 2011. Growth and yield response of three aeroponically grown potato cultivars (Solanum tuberosum L.) to different electrical conductivities of nutrient solution. Amer. J. Potato Res. 88:450-458.

Choi, K.Y., K.Y. Paek, and Y.B. Lee. 2000. Effect of air temperature on tipburn incidence of butterhead and leaf lettuce in a plant factory, p. 166-171. In: C. Kubota and C. Chun (eds.). Transplant production in the 21st century. Springer, Berlin, Germany. 


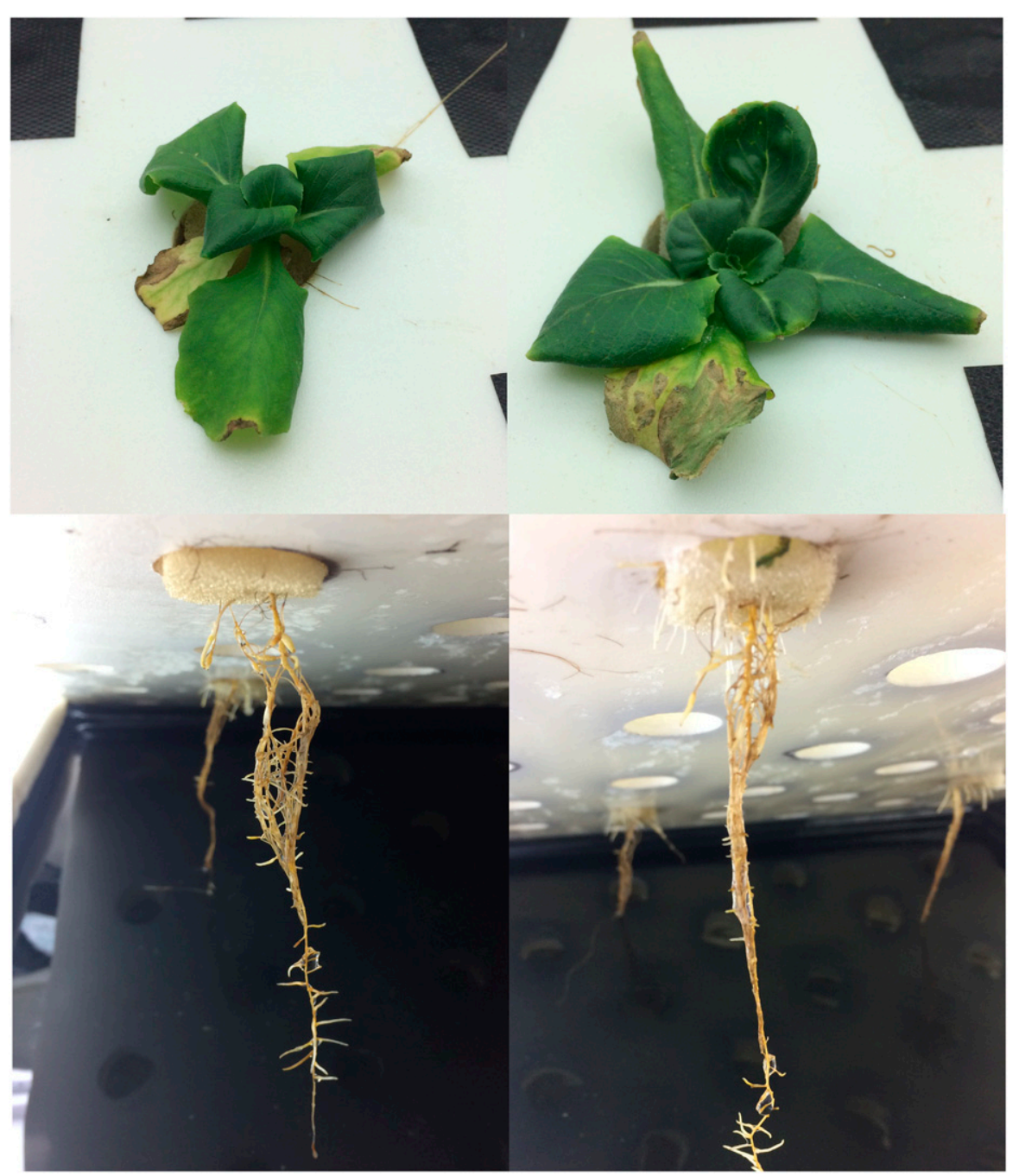

Fig. 11. Butterhead lettuce seedlings grown using a regenerative self-priming pump. The photo was taken on day 4 after the seedlings were transplanted into hydroponic systems.

Cloutier, G.R., M.A. Dixon, and K.E. Arnold. 1997. Evaluation of sensor technologies for automated control of nutrient solutions in life support systems using higher plants, p. 851-858. Proc. 6th European Symp. on Space Environmental Control Systems, Noorwijk, The Netherlands, 20-22 May 1997. (ESA SP-400, August 1997).

Despommier, D. 2009. The rise of vertical farms. Sci. Amer. 301(5):80-87.

Engineering ToolBox. 2006. Pump: Volume flow and temperature rise. 8 Nov. 2018. <https://www.engineeringtoolbox. com/pumps-temperature-increase-d_313. html>.

Fischer, G., M.M. Shah, and H.T. van Velthuizen. 2002. Climate change and agricultural vulnerability. Intl. Inst. Appl. Systems Anal., Laxenburg, Austria.

Fong, K.H. and A. Ulrich. 1969. Growing potato plants by the water culture technique. Amer. J. Potato Res. 46:269-272.
Gislerød, H. and R. Kempton. 1983. The oxygen content of flowing nutrient solutions used for cucumber and tomato culture. Scientia Hort. 20:23-33.

Gosselin, A. 1986. Root-zone temperature effects on pepper. J. Amer. Soc. Hort. Sci. 111:220-224.

Goto, E. 2012. Plant production in a closed plant factory with artificial lighting. Acta Hort. 956:37-49.

Hori, Y. 1966. Gravel culture of vegetables and ornamentals. Yokendo 3:60-80 (in Japanese).

Hung, Y.W. 2013. Study on producing strawberry runners with a hydroponics system in plant factory. Natl. Taiwan Univ., Taipei, Taiwan, MS Thesis.

Ikeda, A., Y. Tanimura, K. Ezaki, Y. Kawai, S. Nakayama, K. Iwao, and H. Kageyama. 1992. Environmental control and operation monitoring in a plant fac- tory using artificial light. Acta Hort. 304:151-158.

Ikeda, H. 1985. Soilless culture in Japan. Farming Japan 19(6):36-42.

Jensen, M.H. and A.J. Malter. 1995. Protected agriculture: A global review. World Bank Publ., Washington, DC.

Jones, J.P. 1978. Disease thresholds for downy mildew and target leafspot of cucurbits and late blight of tomatoes. Plant Dis. Rpt. 62:798-802.

Jones, J.B., Jr. 2016. Hydroponics: A practical guide for the soilless grower. CRC Press, Boca Raton, FL.

Jung, V., E. Olsson, S. Caspersen, H. Asp, P. Jensen, and B. Alsanius. 2004. Response of young hydroponically grown tomato plants to phenolic acids. Scientia Hort. 100:23-37.

Kang, J.H., S. KrishnaKumar, S.L.S. Atulba, B.R. Jeong, and S.J. Hwang. 2013. Light intensity and photoperiod influence the growth and development of hydroponically grown leaf lettuce in a closed-type plant factory system. Hort. Environ. Biotechnol. 54:501-509.

Kato, K., S. Maruyama, T. Hirai, K. Hiwasa-Tanase, T. Mizoguchi, E. Goto, and H. Ezura. 2011. A trial of production of the plant-derived high-value protein in a plant factory: Photosynthetic photon fluxes affect the accumulation of recombinant miraculin in transgenic tomato fruits. Plant Signal. Behav. 6:1172-1179.

Kirk, G., A. Ahmad, and P. Nye. 1990. Coupled diffusion and oxidation of ferrous iron in soils. II. A model of the diffusion and reaction of $\mathrm{O} 2, \mathrm{Fe} 2+, \mathrm{H}+$ and $\mathrm{HCO} 3-$ in soils and a sensitivity analysis of the model. Eur. J. Soil Sci. 41:411-431.

Kozai, T. 2007. Propagation, grafting and transplant production in closed systems with artificial lighting for commercialization in Japan. Prop. Ornamental Plants 7:145-149.

Kozai, T., G. Niu, and M. Takagaki. 2015. Plant factory: An indoor vertical farming system for efficient quality food production. Academic Press, Cambridge, MA.

Nelson, G.C., M.W. Rosegrant, J. Koo, R. Robertson, T. Sulser, T. Zhu, C. Ringler, S. Msangi, A. Palazzo, and M. Batka. 2009. Climate change: Impact on agriculture and costs of adaptation. Intl. Food Policy Res. Inst., Washington, DC.

Ortega, M., M. Moreno, J. Ordovas, and M. Aguado. 1996. Behaviour of different horticultural species in phytotoxicity bioassays of bark substrates. Scientia Hort. 66:125-132. 


\section{Research Reports}

Rosenzweig, C. and D. Liverman. 1992. Predicted effects of climate change on agriculture: A comparison of temperate and tropical regions, p. 342-361. In: S.K. Majumdar (ed.). Global climate change: Implications, challenges, and mitigation measures. Pennsylvania Acad. Sci., Erie, PA.

Runia, W.T. 1993. A review of possibilities for disinfection of recirculation water from soilless cultures. Acta Hort. 382:221-229.

Salisbury, F.B. and C.W. Ross. 1992. Plant physiology. 4th ed. Brooks Cole, Boston, MA.

Son, J.E. and T. Takakura. 1987. A study on automatic control of nutrient solutions in hydroponics. J. Agr. Meteorol. 43:147-151.

Sonneveld, C. 1993. Hydroponic growing in closed systems to safeguard the environment. p. 21-36. Austral. Hydroponic Conf. Monash Univ., Monash, Australia.

Suzuki, Y., Y. Shinohara, M. Shibuya, and H. Ikeda. 1984. Recent development of hydroponics in Japan. ISOSC Proc. Sixth Intl. Congr. Soilless Cult, Wageningen, The Netherlands, p. 661-672.

Wilson, J.P., K.E. Gerhart, G.A. Nielsen, and C.M. Ryan. 1992. Climate, soil and crop yield relationships in Cascade County, Montana. Appl. Geogr. 12:261279.
Yamazaki, K. 1982. Nutrient solution culture. Pak-kyo Co., Tokyo, Japan (in Japanese).

Yamori, W., G. Zhang, M. Takagaki, and T. Maruo. 2014. Feasibility study of rice growth in plant factories. Rice Res. 2(1):119.

Yu, J.Q. and Y. Matsui. 1993. Extraction and identification of phytotoxic substances accumulated in nutrient solution for the hydroponic culture of tomato. Soil Sci. Plant Nutr. 39:691-700.

Zekki, H., L. Gauthier, and A. Gosselin. 1996. Growth, productivity, and mineral composition of hydroponically cultivated greenhouse tomatoes, with or without nutrient solution recycling. J. Amer. Soc. Hort. Sci. 121:1082-1088. 